\title{
Probe to the Roles Played by Tutors in the Course of Agro-products Quality Control in the Distance and Open Education Pattern
}

\author{
Li Zhang \\ Department of Agriculture and Medicine, Hunan Radio \&TV University, Changsha, China \\ Email: $136325891 @ q q . c o m$
}

\begin{abstract}
The teaching model of the distance and open education is to advocate the "learner centered", from the traditional school education to the teaching teachers' guidance and students' learning autonomy, and the transformation in the teaching mode under the use of the coexistence and interaction between various teaching forms and various teaching media. The role of Curriculum learners' guidance tutors has changed, from knowledge spreaders to the instructor, guide, tutor and counselor guide for students' learning, to stimulate the subjective initiative of students, and to cultivate students' the autonomous learning ability.
\end{abstract}

Keywords-open education, teaching mode, curriculum learning guidance, role change

\section{INTRODUCTION}

The core of modern distance and open education lies in the teacher's instructive teaching and student's autonomous learning. As for the curriculum guidance, it is also a shift from the traditional closed pattern of teacher-centered and face-to-face teaching-oriented to the modern distance and open education pattern featuring tutors as the "guidance", learners studying independently with multiple media supporting. It requires that the tutors should adopt various methods in curriculum guidance, changing the roles from the knowledge transmitter to student's guider, mentor, counselor and communicator, so as to fully mobilize student's initiative and creative abilities, complete teaching tasks as well as the teaching objectives. Taking the course of agro-products quality control as an example, this paper probes to the roles played by tutors in the distance and open education pattern.

Agro-products quality control is a professional courses established by China Central Radio \& TV University for the students majored agricultural technology. It serves for "the plan of one college student for one village" (hereinafter referred to as "one college student for one village") and the students are most grass-roots cadres and some large farmers who are low-educated, so that they lack of the ability of study in virtue of distance education. Besides, the learning time is hard to guarantee, so it is rather difficult for them to study alone and makes more specific requirements for the tutors.

\section{II .THE CURRICULUM LEARNING GUIDANCE TUTOR IS THE GUIDANCE IN STUDENT'S ACADEMIC CAREER}

Starting from the enrollment, the tutors should guide students to establish the idea of distance and open education, to take in the new-type learning model and to get familiar to the characteristics of distance and open education so as to master web-based learning rules and the manner of open learning.

Before class, the tutors should cultivate the freshmen in accordance with Learning guide for Open Education, such as the questions: What the meaning of distance and open education? What cognitional shifts should be adopted in the learning process of distance and open education? What are the characteristics of "one college student for one village"? And what sessions can be included in the teaching process? Try to guide students to properly use online teaching platform of China Central Radio \& TV University and give instructions to their majors and curricula-variables; to help the freshmen get familiar to the characteristics of the open education so as to convert their learning beliefs as well as adapt to the surroundings and basic teaching sessions.

At the start of the course, the tutors should guide students to cultivate the abilities of self-thinking, linking theory with practice, dealing with problems flexibly and efficiently. By means of these, the students can understand the curriculum's design idea, learning goal and the assignments so as prepare for the coming tight learning schedule.

\section{THE CURRICULUM LEARNING GUIDANCE TUTOR IS THE GUIDANCE IN STUDENT'S LEARNING METHODS.}

In the process of curriculum guidance, the role played by the tutor is to "teach a man to fish": teach students how to study efficiently in the distance and open education pattern. What's more, tutors should guide students how to learn in the whole process of teaching, which includes direct students how to put forward difficulties and find doubt points; how to write reading notes; how to choose learning media properly and how to get learning support. It can improve student's abilities of acquiring knowledge and solving problem through network and multimedia by teaching them how to use learning media as well as acquiring learning resource and teaching information. 
Tutors will instruct students to choose proper learning style and media in accordance with the practical circumstance and course characteristics that the students in the plan of "one college student for one village" have weak self-study ability and are lack of learning methods. What's more, tutors should allocate learning time properly to let students master the general approach of self-learning, listening to the class, doing assignments and fulfilling practice as well as stimulate them to study independently, cooperatively collectively.

In the aspect of agro-product managerial learning, tutors provide the following proposals: first, have a clear-cut understanding of the target of agro-product management and bear in mind the learning purpose, which can motivate your learning interest; second, make a learning plan and choose a suitable style, just like "one college student for one village", which focus on adults with the target of improving education background and working skill. However, conflicts between work and study as well as the living pressure make it hard for students to attend class on schedule, so for the students who can surf the Internet, they can study the curse through network and understand the details and instructions; while for the students who cannot surf the internet, they can take advantage of multimedia disk courseware and the counseling information to study and even finish homework by themselves; third, study carefully the teaching materials; fourth, make extensive use of the teaching resources; fifth, optimize the face to face teaching course and finally, take an active part in various teaching activities.

Tutors also introduce the learning categories and methods of agro-product quality management to students. For example, they have introduced the teaching materials as well as the formative assessment and curriculum tutorial; the materials on the network, including textual tutoring to key and difficult points, the new theory and trend of the development of agro-product quality management and the current case analysis. Taking the online platform in Hunan Radio and Television University as an example, tutoring, final exam review, practical assignments and IP courseware are all helpful for the students to master knowledge and deal with the exams. Besides, other column like reference material can broaden student's scope of knowledge. In accordance with needs and interest, students can study these materials on the network, such as listing the relative source websites: online platform in Hunan Radio and Television University, "one college student for one village" distance teaching net in Hunan Radio and Television University, Chinese agricultural product quality safety net, Agricultural product quality safety information net and Hunan agroproduct safety monitoring information net.

\section{THE CURRICULUM LEARNING GUIDANCE TUTOR IS THE CURRICULUM KNOWLEDGE COUNSELOR FOR STUDENTS LEARNING}

According to the current students' condition of "one college student for one village", the theoretical basis is relatively poor, and students who can autonomous learning is pretty little. Tutors of guidance learning should according to the specific content of the students' autonomous learning condition and curriculums, base on the actual fact to focus on the analysis of the key points, difficulties and answers to doubts of rural students; they should guide students to straighten out the knowledge system of the courses, grasp the key points, and break through the difficulties; they should encourage students to explore and summarize the learning method.

Curriculum guidance learning tutors, according to the arrangement of the course syllabus on quality management of agricultural products and the scheme of integration of multimedia teaching, lecture the teaching form and the design of teaching activities of the course to the students, which there is the 18 units for students to carry out autonomous learning, online learning, and the two-way video class and the other kinds of forms, let the students have a basic understanding of the course contents and learning requirements, so that it is benefit for students to have the independent and individualized learning.

Curriculum guidance learning tutors explain the basic concept, basic knowledge, basic methods and key content of each unit. They should guide the learners how to read a book, how to find out key points, put forward difficulties, found doubts, how to do reading notes, and how to make systematical management of the knowledge, write the difficulty analysis, doubts resolving, and innovative ideas etc. They can use various forms of the remote education, such as online communication, telephone answering, online counseling, E-mail response and solving difficulties with QQ. For instance, learning the fifth unit of organic products, pollution-free agricultural products and green food, when teachers explain these contents, they would point out that the key point for learning this unit is to grasp the concept of the organic agriculture and organic agricultural products, the concept of pollution-free agricultural products and green food; the basic concept to grasp is the organic agriculture and organic products, pollution-free agricultural products and green food.

Curriculum guidance learning tutors in the online realtime communication platform comment and appraise four times ordinary homework of the formative assessment books. By commenting and appraising the homework, teachers can understand the students' common problems in learning, and point out the methods and means to solve the problem, and help students to improve their learning summaries, so as to help students grasp the basic knowledge and the basic theory, and while grasp the correct analysis of the problem, the methods to solve the problem.

At the end of the term, the teacher should make the final review for the exam, which is mainly the summary of the contents of teaching materials, and the screening, classification and integration of all kinds of teaching resources, clearing and defining the focus, to enable students to grasp the key and difficult points with purpose in a short period of time, in order to make better preparation for the test. Such as through online real-time exchange activities, the teaching activities of the curriculum interactive community and other forms of activities, they make students make the review, mainly including the course examination 
mode, examination time, the example of samples, review methods and the evaluation of knowledge points in each unit.

In the guidance learning course of the students' studying the content, the coach of teachers is to help students run through the whole process of learning the course content. The teachers act as a source of information for students, and help students clear up all kinds of obstacles on learning, and enhance their confidence and motivation in learning.

\section{CONCLUSION}

The students in "one college student for one village" make the use of their spare time to learning autonomy, and the condition of surfing the Internet in rural area is not good. Thus, in their process of learning, some part time is still in online virtual space, which will inevitably always these or those obstacles appear, and affect the normal learning, even have a thought of beating a retreat. Only if the teachers clear up these obstacles, the students will succeed in their study and acquire some knowledge.

In the process of students to learn the quality management course of agricultural products, guidance learning tutors should guide students' obstacles of practice and time. For example, when students learn the eighteenth unit of case analysis on the quality evaluation of agricultural products, they are required to use this curriculum knowledge, to learn the comprehensive quality assessment identified for a specific product of the supplier and the demander, to discuss more the concern points and reflection points of students learning in reality, to organize the students to plunge into life in the internship and practical training, and to grasp the theoretical and realistic starting points and breaking points. The students in "one college student for one village" are under the dual pressure of the work and family, in which their learning time is liable to be occupied. Therefore, teachers should inform the students of the related activities of course teaching, and let the students reasonably arrange their time; the teachers should also make full use of the non-real-time functions of network teaching, let the students have as much discretion as possible in their learning time. Through these counseling measures, it is beyond doubt for guidance learning teachers to play a role in students' mental health, the accomplishment of their homework on time, the acquirement of their life-long learning abilities.

In short, in the mode of modern distance and open education, there is the essential difference between the role of curriculum guidance learning tutors and the role of those in traditional education, and it is multiple, and their responsibilities are in many ways. To play the multiple roles better of a good curriculum guidance learning teachers, it must be required for them to liberate from the shackles of the traditional roles, from the simple knowledge spreaders to the instructor, guide, tutor and counselor for the students' learning, which is better for them to adapte to the needs of the learning community.

\section{ACKNOWLEDGMENT}

This research is supported by the 12th five-year plan project in hunan province(No. XJK013CCR004).

\section{REFERENCES}

[1] Zhou Jiezhen, Wang Shaohua. Analysis of Teachers' Roles under Distance Open Education Pattern [J]. Chinese Distance Education, 2002.03: 22-26.

[2] Zhang Li. Grasp the Main Links of Teaching and Improve the Teaching Quality of “One College Student for One Village” [J]. Entrepreneurs World, 2011.10: 109.

[3] Li Zhiping. Study on the Problem and Countermeasure of Learners' Learning Adaptability of "One College Student for One Village Plan" [J]. Chinese Distance Education, 2008.10: 42-44.

[4] Lu Yao. Research on the Guidance Learning Mode of the RTVU's Courses for English Major in Open Education [J]. Journal of Liaoning Radio and TV University, 2009.06: 30-32

[5] Biography: Zhang Li (1969- ), female, the Han nationality, Changsha City, associate professor, Hunan Agricultural University, Master's degree in agricultural extension ( planting direction ).

[6] Zip code: 410004, Address: No. 168, Green Road, Changsha City ( Hunan Radio and TV University, the distance education building 412 ), Recipient: Zhang Li, Tel: 13787319667. 